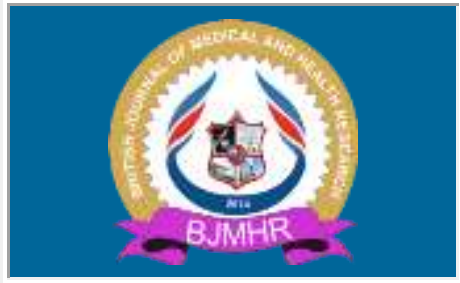

\title{
BJMHR
}

British Journal of Medical and Health Research Journal home page: www.bjmhr.com

\section{Student Centred Learning Challenges Among Lecturers In Four Kenya Medical Training College Campuses Within South Nyanza Region, Kenya}

\author{
Eliakim M. Konje*, Motari Omariba \\ Department of Physiotherapy, Kenya Medical Training College, Homa Bay Campus
}

\section{ABSTRACT}

Students who are admitted within 68 Kenya Medical Training College (KMTC) Campuses for various healthcare programs are highly qualified and they are chosen through a competitive admission criterion. However, their performance in college exams does not reflect the same. For instance, approximately $26 \%$ of students sat for supplementary exams in the year 2017 . This performance trend implies that there may be challenges in the implementation of studentcentered learning (SCL) approaches among the lecturers. Due to this, the researcher decided to conduct a research study on SCL challenges among lecturers. Cross-sectional descriptive study with researcher-administered questionnaires among 61 lecturers (both internal and external) was employed within KMTC-Campuses within South Nyanza Region namely; Nyamira, Kisii, Homa Bay, and Migori. The study adopted purposeful sampling to select KMTC-Campuses and saturated sampling of the participants. The finding concluded that although the ratio of students to lecturers (1:45) was within the recommended standards, the level of awareness and practice of SCL by the lecturers was low within the KMTC-Campuses. The study indicated that lecturers had little involvement to enhance SCL activities within their various campuses even though their instructional design has an impact on SCL especially on new approaches to tasks, activities and classroom discourse. The study concluded that the inadequacy of SCL resources affects its effective implementation. The researchers recommend that further studies be done on the exposure of students to various participatory learning methodologies and the provision of SCL resources.

Keywords: Challenges, lecturers, implementation, student-centered learning 


\section{INTRODUCTION}

In Medical Education, development research has shown that teaching and learning concept is moving from behaviorist theoretical belief which states that learning was perceived to be influenced by external factors. For example, in teacher-centered learning (TCL) where the power is with the expert teacher, the student becomes passive, apathetic and bored ${ }^{1}$. Research has shown that knowledge is acquired rather than being impacted on students by their teachers thus enabling students to become lifelong learner ${ }^{2}$. SCL can only be achieved if teachers are aware, knowledgeable and can create a conducive classroom learning environment that is more active, interactive and communicative ${ }^{3}$. However, a study in Oman, states that numerous challenges are facing the implementation of SCL, particularly lack of sufficient awareness of teaching staff on $\mathrm{SCL}^{3}$. This study, therefore, intends to find out the SCL awareness challenges in four Kenya Medical Training College (KMTC) Campuses within the South Nyanza Region. In South Africa, student-centered learning is an increasingly popular approach, though it is not giving a clear understanding of who students are and what their needs are for them to be provided with quality education ${ }^{4}$. Norms, values, and practices from schools and homes should be aligned with norms, values, and practices of the university, but for this to be successfully achieved; learning and teaching resources should be available ${ }^{4}$. In Kenya, there is the paucity of information concerning the availability of resources for effective SCL. Hence, it will be worthwhile for the researchers to determine challenges in resource availability for effective teaching and learning within the four KMTCs in South Nyanza Region, Kenya.

Students admitted to various KMTC-campuses within Kenya for various courses are highly qualified and they are chosen through a competitive admission criterion. However, their performance in college exams does not reflect the same. Out of 107 students in the physiotherapy department, 21 of them sat for supplementary exams in the year 2017. This is a trend also observed in other departments within the campus. This translates to $80 \%$ pass as opposed to $90 \%$ pass in line with KMTC - Homa Bay Campus, quality management system objective. This mediocre performance trend implies that there may be challenges in the implementation of SCL approaches among the lecturers. However, there is a paucity of information about SCL within KMTC Campuses in Kenya. Further, lecturers are required to take a leading role in facilitating students in SCL. It is against this background that the researchers decided to conduct a research study on Student-Centred Learning challenges among lecturers in Four KMTCs within South Nyanza Region, Kenya.

\section{MATERIALS AND METHOD}

\section{Study area}


The study was carried out in the KMTC-Campuses within the South Nyanza Region, located within the South Western part of Kenya. The region has six KMTC-Campuses namely; Kisii, Nyamira, Homa Bay, Rachuonyo, Migori, and Kuria. The campuses offer diploma and certificate programs in various healthcare disciplines which include community health nursing, clinical medicine, community nutrition, pharmacy, laboratory sciences, physiotherapy among others. The study was conducted in KMTC Kisii Campus is within Kisii town in Kisii County, KMTC Nyamira campus in Nyamira town within Nyamira County, KMTC Homa Bay campus in Homa Bay township within Homa Bay County and KMTC Migori campus is in Migori town within Migori County.

\section{Study population}

The study population was all the lecturers in four KMTC-Campuses within South Nyanza Region. The four campuses within the region had approximately 61 lecturers (both KMTC staff and part-time lecturers).

\section{Study design}

The study design was a descriptive cross-sectional study, which used quantitative approaches to establish the challenges of student-centered learning in KMTC-Campuses within the South Nyanza Region. The researcher-administered questionnaire on challenges faced by lecturers in the implementation of SCL was modified after a pre-test was done. The questionnaire was constructed and administered in the English language since it is the national language of Kenya and the main language of instruction used in educational institutions within the country.

\section{Procedure}

The pre-testing of the questionnaire was carried out at KMTC Rachuonyo. Campus. The researcher used a purposeful sampling technique to select the KMTC-Campuses and saturated sampling method to select participants. Saturated sampling technique was adopted because it collected data from every member of the population being studied since they were too few to make a sample out of them. Saturated sampling technique often results in enough respondents to have a high degree of statistical confidence in survey results ${ }^{5}$. Data collection was conducted from $1^{\text {st }}$ October- $30^{\text {th }}$ November 2018, after authorization from KMTC ethical Committee, Chief Executive Officer of KMTC and from the various KMTC-Campuses Principals. The sampled lecturers were informed about the study, assured their confidentiality before participating in the study, clarifications on specific questions were done to the participants and later on they signed the informed consent before participating in the study. Data collected was sorted out and checked for completeness. Sorted data was analyzed using Microsoft Excel version 2016 for Windows 10. Analyzed data was presented in form of tables, graphs, histograms, and pie-charts. 


\section{RESULTS AND DISCUSSION}

\section{Demographic characteristics of the participants}

A total of 61 lecturers were approached to participate and only 53 agreed, of those, 8 questionnaires were discarded because they were incomplete. Hence, the total number of participants was 45 . The response rate of the study was $74 \%$. The majority of the Lecturers were from KMTC Homa Bay Campus (56\%), followed by KMTC Kisii and Migori Campuses at $16 \%$ and $13 \%$ were from KMTC Nyamira Campus.

The Departments' respondents were from Nursing (47\%), Physiotherapy (18\%), Nutrition (16\%), Clinical Medicine (16\%), Medical Engineering (2\%) and Orthopaedic and Trauma $(2 \%)$. Most of the respondents were external lecturers $(51 \%)$ while internal lecturers who participated were $49 \%$.

Most lecturers have taught in KMTC for (2-5) years (36\%), 31\% of participants have taught in KMTC for 1 year and below, while, $7 \%$ of the participants have taught in KMTC for 21 years and above. Most of the lecturers have a Bachelor of Science Degree (60\%) in KMTC, 20\% have Higher National Diploma, while those who have Diploma and Master's Degree are $7 \%$ and $13 \%$ respectively.

In terms of gender; most lecturers are male (62\%) in KMTC, while, female lecturers are $38 \%$. The majority of the lecturers are aged between $(30-39)$ years $(31 \%)$, followed by $(50-59)$ years $(27 \%)$, while the least lecturers age bracket were those of 60 years and above (4\%). Most of the participants were not trained in Medical Education (58\%). The ones who were trained as a medical educator were $42 \%$. Majority of the lecturers facilitate Human Anatomy and Physiology (29\%) while a few lecturers at 2\% teaches Electronics and Laboratory equipment, Teaching and learning Methodology, Medical-Surgical Nursing and Ophthalmology

Table 1: Demographic characteristics of the study sample $(n=45)$

\begin{tabular}{lll}
\hline $\begin{array}{l}\text { Variable } \\
\text { KMTC Respondents }\end{array}$ & Frequency & Percentage (\%) \\
\hline Homa Bay & 25 & 56 \\
Kisii & 7 & 16 \\
Nyamira & 6 & 13 \\
Migori & 7 & 16 \\
Departments & & \\
Nursing & 21 & 47 \\
Clinical Medicine & 7 & 16 \\
Nutrition & 7 & 16 \\
Physiotherapy & 8 & 18 \\
Medical Engineering & 1 & 2 \\
Orthopedic and Trauma & 1 & 2 \\
Lecturers Terms of Service & & \\
Internal Lecturers & 22 & 49 \\
External Lecturer & 23 & 51 \\
\hline
\end{tabular}




\section{Duration Lecturers has taught at KMTC}

1 Year and Below

$14 \quad 31$

(2 - 5) Years

$16 \quad 36$

(6 - 10) Years

$7 \quad 16$

(11 - 20) Years

$5-11$

21 Years and Above

3

7

Lecturers level of Education

PHD

Msc/MA/MMED

$0 \quad 0$

$\mathrm{BSc}$

$6 \quad 13$

HND

$27 \quad 60$

Diploma

920

Lecturers' Gender

Male

$3 \quad 7$

Female

$28 \quad 62$

$17 \quad 38$

Lecturers' Age

$(20-29)$ Years $\quad 920$

(30 - 39) Years $\quad 14 \quad 31$

(40 - 49) Years $\quad 8 \quad 18$

$(50$ - 59) Years $\quad 12 \quad 27$

60 Years And Above

24

Lecturers' trained in Medical Educator

Trained

$19 \quad 42$

Not Trained

$26 \quad 58$

\section{Awareness Level}

\section{Students Population per Class}

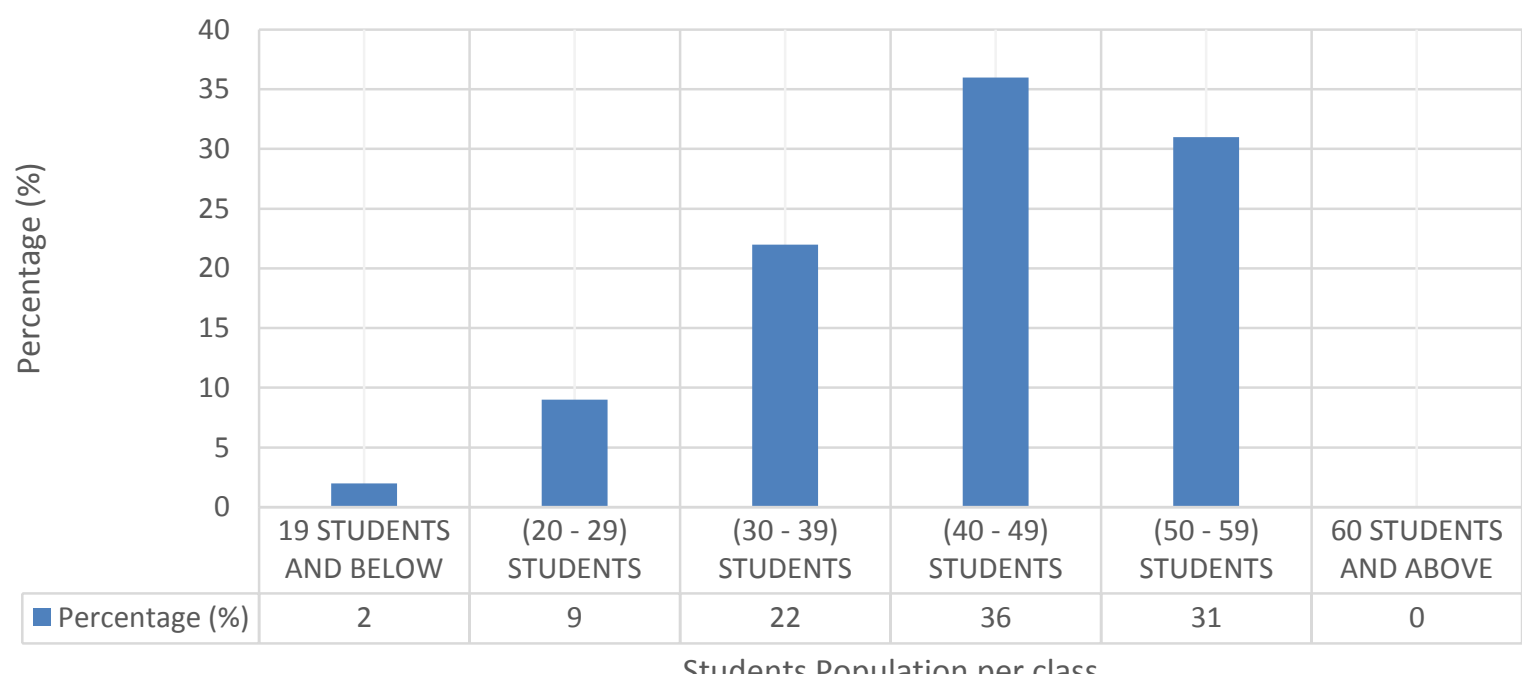

Students Population per class

Key:

Percentage $=\mathrm{n} / 45^{*} 100$

\section{Figure 1: Lecturers' students' population per class}

$36 \%$ of the respondents have a class student's population of $(40-49)$ students, followed by $(50$ - 59) students' population $(31 \%)$, then $(30-39)$ students' population $(22 \%)$. The list of 
students' population per class is (20 -29) students and then 19 students and below as $9 \%$ and $2 \%$ respectively. There was no student population per class of 60 students and above.

\section{Lecture session duration}

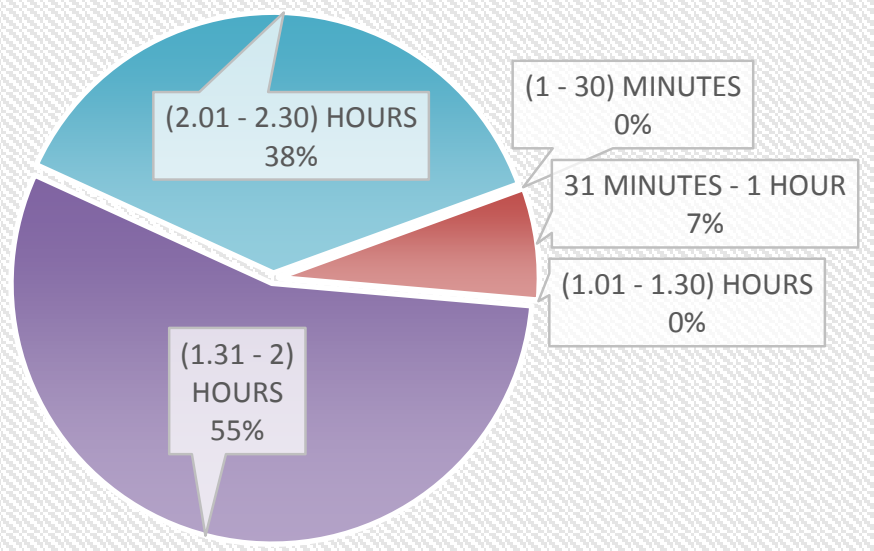

Key:

Percentage $=\mathrm{n} / 45^{*} 100$

\section{Figure 2: Duration of Lecture session during teaching and learning}

The majority of the respondents, 55\% indicated that their lecture session takes $(1.31-2)$ hours per module. $(2.01-2.30)$ hours was being taken by $38 \%$ of the respondent in the lecture session and $7 \%$ for 31 minutes -1 hour.

\section{Sufficiency of time allocation per session}

$51 \%$ of the respondents were satisfied with the sufficiency of time allocation per modular teaching and learning session, while, $49 \%$ of the respondents were unsatisfied. 


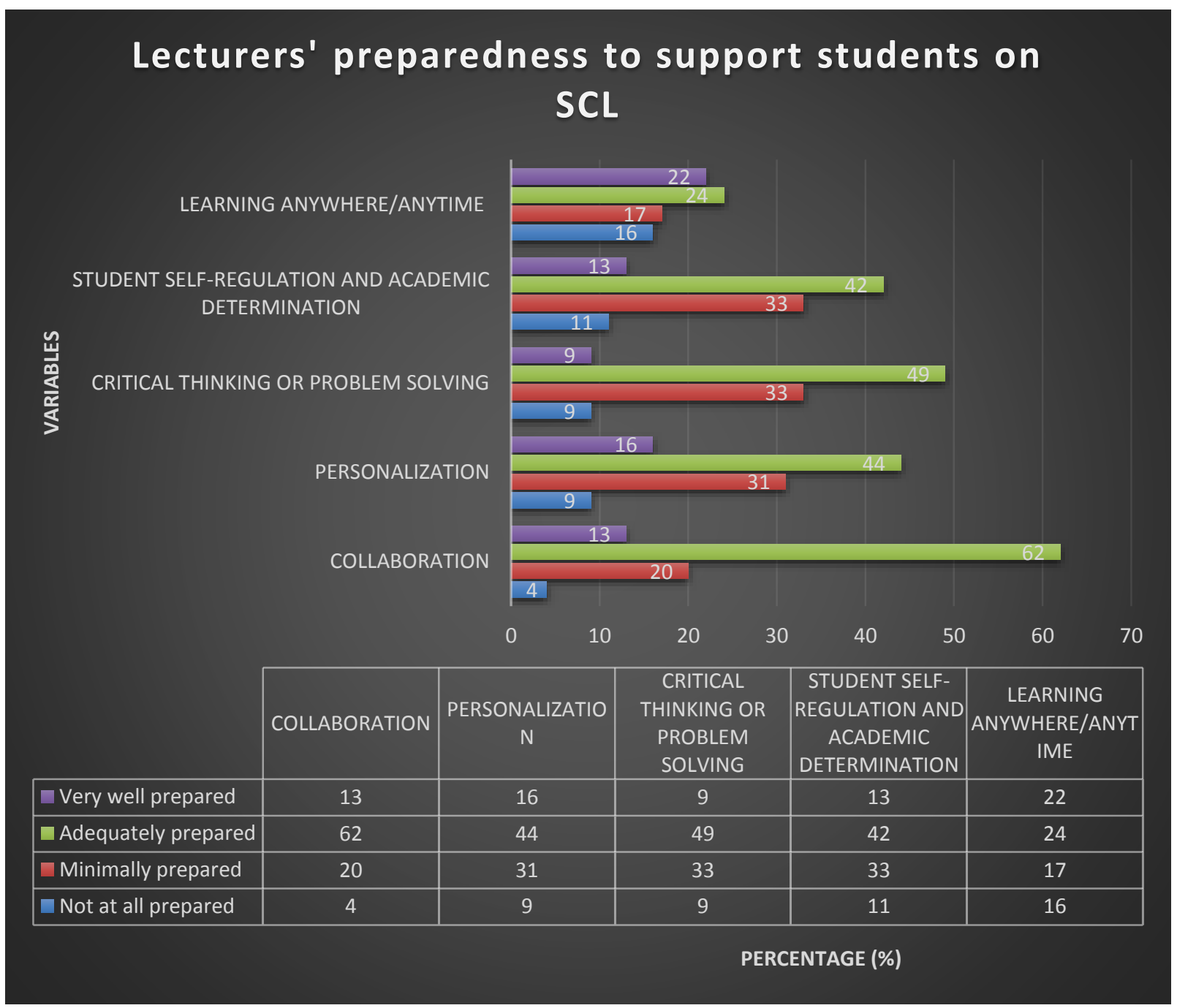

Key:

Percentage $=\mathrm{n} / 45^{*} 100$

\section{Figure 3: Lecturers' preparedness to support students on SCL}

Most lecturers are adequately prepared to support students on SCL as follows; Collaboration (62\%), Personalization (44\%), Critical thinking or problem solving (49\%), Student selfregulation and academic determination (42\%), and, in Learning anywhere/anytime (24\%). It is important to note that also quite a several lecturers are minimally prepared to support students on SCL as follows; collaboration (20\%), personalization (31\%), Critical thinking or problem solving (33\%), Student self-regulation and academic determination (33\%), and, in Learning anywhere/anytime (17\%).

\section{Lecturers' intention on SCL advocacy}

The majority of the respondents (98\%) will advocate for SCL, while, $2 \%$ of the respondents will not advocate for SCL. 


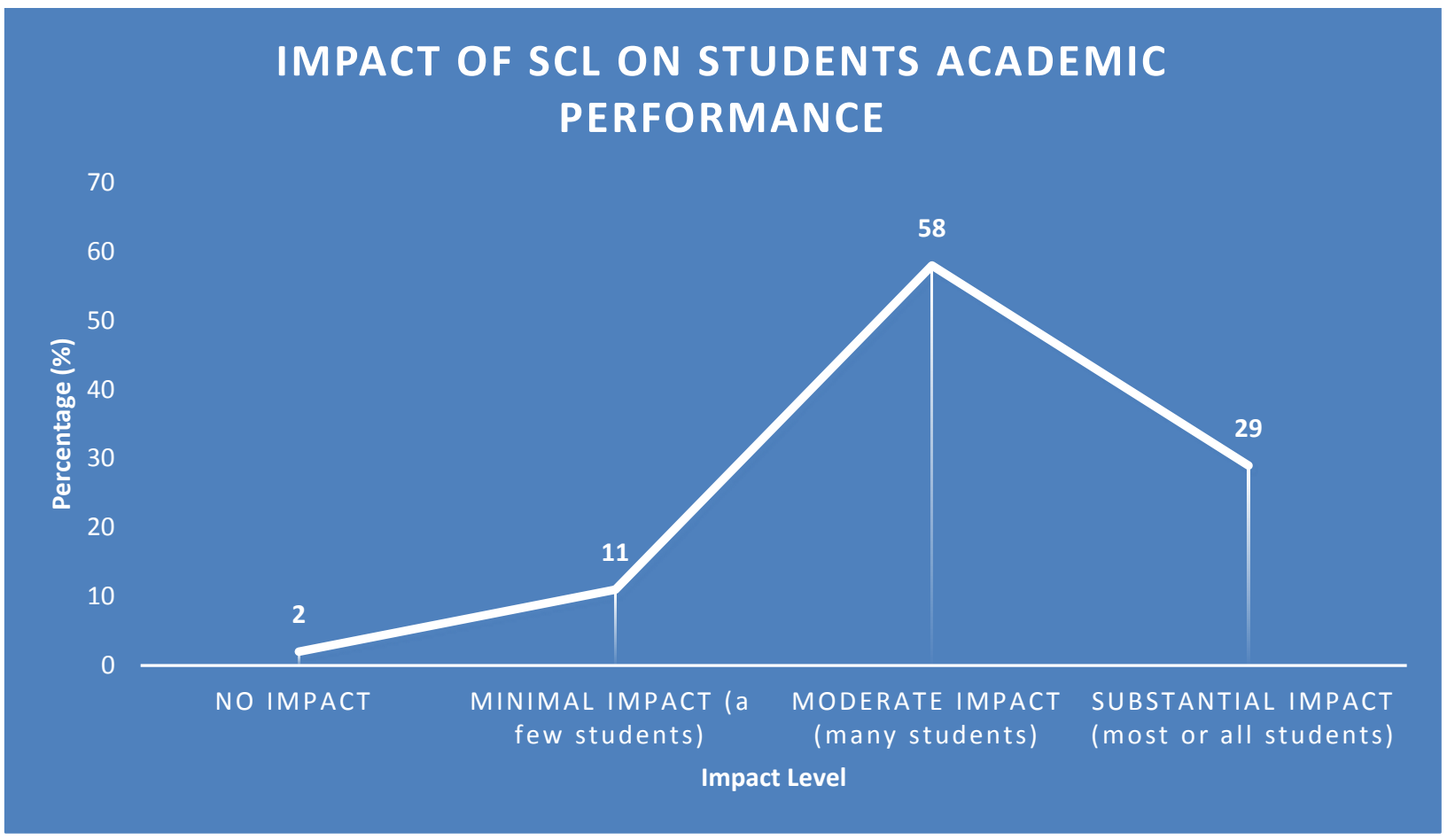

Key:

Percentage $=\mathrm{n} / 45^{*} 100$

\section{Figure 4: Impact of SCL on students' academic performance}

$58 \%$ of the Lecturers state that SCL has a moderate impact on the student's academic performance. $29 \%$ of the lecturers state that SCL has a substantial impact on the student's academic performance. A few lecturers indicated that there no impact (2\%) and minimal impact (11\%) of SCL on student's academic performances.

\section{Views of Lecturers on items leading to enhancing SCL}

The majority of respondents (78\%) view teaching students study skills and self-evaluation is very important in enhancing SCL. While $51 \%$ of the respondents indicated that encouraging students to come up with learning contracts is very important in enhancing SCL. $56 \%$ of respondents view giving students autonomy to determine what they learn.is very important in enhancing SCL. The following are the strategies lecturers' uses to encourage students to become good student-centered learners:

1. Expose students to more information both in class and clinical setting experiences and encouraging wide reading

2. Facilitate students on professional ethics regarding their roles and responsibilities within the community so that they take charge of their learning.

3. Provide students with more learning materials.

4. Mentor students to positively change their attitude towards SCL

5. Frequently examining them through various methods e.g. class discussions, role-plays and group discussions to evaluate their progress 


\section{Resources for implementation of SCL}

$84 \%$ of the respondents indicated that there are not enough resources available within the department to enhance SCL. Majority of respondents (64\%), state that the most commonly used resources within the department is the library, followed by Clinical Site/hospital (51\%), then Computers and internet (44\%). Lastly, they indicated that the Skills lab/Demonstration room and Community placement site are least used as resources for SCL within the department, $33 \%$, and $22 \%$ respectively.

Table 2: Availability and commonly used resources within the department to enhance SCL

\begin{tabular}{lll}
\hline Variable & Frequency & Percentage (\%) \\
\hline Enough resources availability for & & \\
SCL in your department & 7 & 16 \\
Yes & 38 & 84 \\
No & & \\
Most commonly used resources for & & \\
SCL in the department & 20 & 44 \\
Computers and internet & 23 & 51 \\
Clinical site /hospital & 15 & 33 \\
Skills lab / demonstration room & 29 & 64 \\
Library & 10 & 22 \\
Community placement site & & \\
\hline
\end{tabular}

Key:

Percentage $=\mathrm{n} / 45^{*} 100$

\section{Impact of SCL instructional design on students' teaching and learning}

$56 \%$ of respondents' show that their instructional design has a moderate impact (that is, new approaches to tasks, activities, and classroom discourse), followed by substantial impact at $18 \%$ (that is, fundamentally reshaped how I teach and what I expect of students), then $16 \%$ at minimal impact (that is; minor changes in tasks, activities or classroom discourse), and, 9\% of respondents indicated that their SCL instructional design has no impact on students' teaching and learning.

\section{Lecturers' suggestions on their responsibilities towards the acquisition of resources for} SCL

The majority of respondents $(87 \%)$ suggest that it is their responsibility to make sure that resources for SCL are available for students. The rest $13 \%$ of the respondents decline that it is not their responsibility to avail resources for SCL.

Table 3: Frequency of acquisition of resources for SCL

\begin{tabular}{lll}
\hline Frequency of acquisition of resource & Frequency & Percentage (\%) \\
\hline Rarely & 12 & 31 \\
Frequently & 17 & 44 \\
Very frequently & 10 & 26 \\
\hline
\end{tabular}


Key:

Percentage $=\mathrm{n} / 39 * 100$

$44 \%$ and $26 \%$ of the respondents frequently and very frequently acquire resources for SCL, respectively. $31 \%$ of respondents rarely acquire resources for SCL.

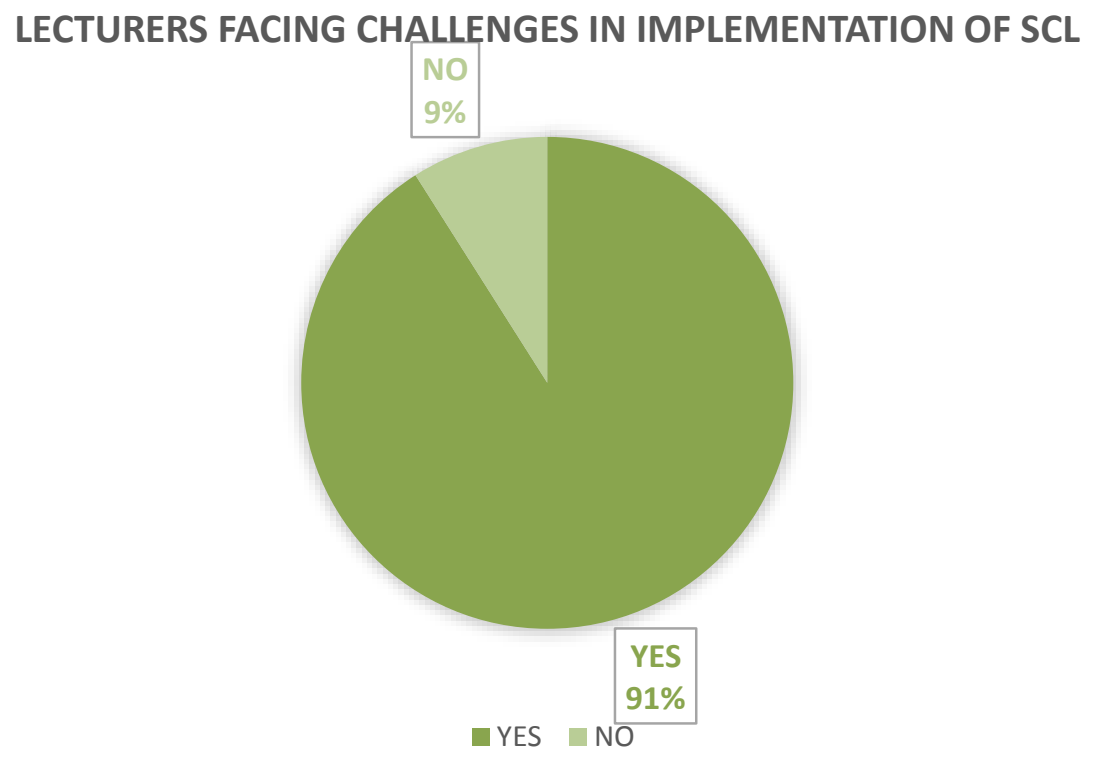

Key:

Percentage $=\mathrm{n} / 45^{*} 100$

Figure 5: Lecturers facing challenges in the implementation of SCL

$91 \%$ of the respondents face challenges in the implementation of SCL within the four KMTC-

Campuses in the South Nyanza Region.

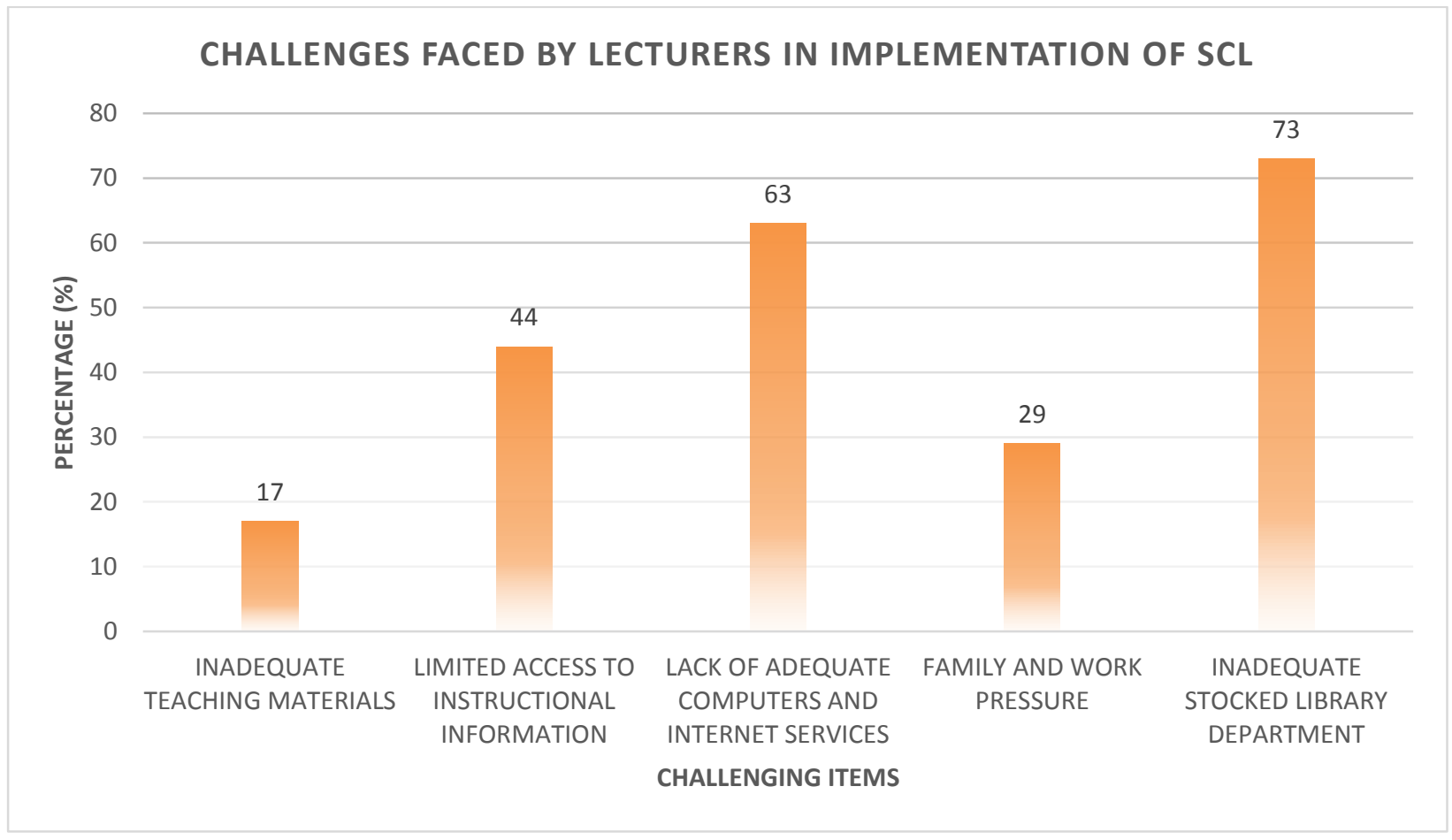

Key: 
Percentage $=\mathrm{n} / 41 * 100$

\section{Figure 6: Challenges faced by lecturers in implementation of SCL}

The majority of the respondents $(73 \%)$ stated that the inadequately stocked Library department imposes a major challenge in the implementation of SCL. It was followed by $63 \%$ of respondents who indicated that the lack of adequate computers and internet services contributes to challenges in the implementation of SCL. Limited access to instructional information, family and work pressure plus inadequate teaching material also impose challenges in the implementation of SCL at $44 \%, 29 \%$, and $17 \%$, respectively.

\section{Lecturers' contribution to SCL}

\section{Lecturers involvement to enhance SCL activities in their Campus}

Moderate involvement (51\%) has been engaged by respondents to enhance SCL activities, while, $40 \%$ of the respondents have had minimal involvement in enhancing SCL activities in their respective KMTC Campuses within South Nyanza Region. 9\% of the respondents have had substantial involvement in enhancing SCL activities within their campuses.

\section{Lecturers' ability to notice inactive students during Lecture sessions}

$93 \%$ of the respondents notice inactive students during their lecture sessions, while, $7 \%$ do not. Due to this, the respondents who notice inactive students administer the following measures;

1. Directly engaging them through class participatory interactive learning sessions e.g. Asking questions, individual/group work, plenary discussions, class presentations

2. Have an interactive counseling session with them to establish the etiology of their inactiveness in class and let them come up with appropriate solutions to make them active in class.

3. Have them take micro-break sessions in between lectures.

4. Encourage adequate preparation for the lecture session by giving class topics of the next lecture. 


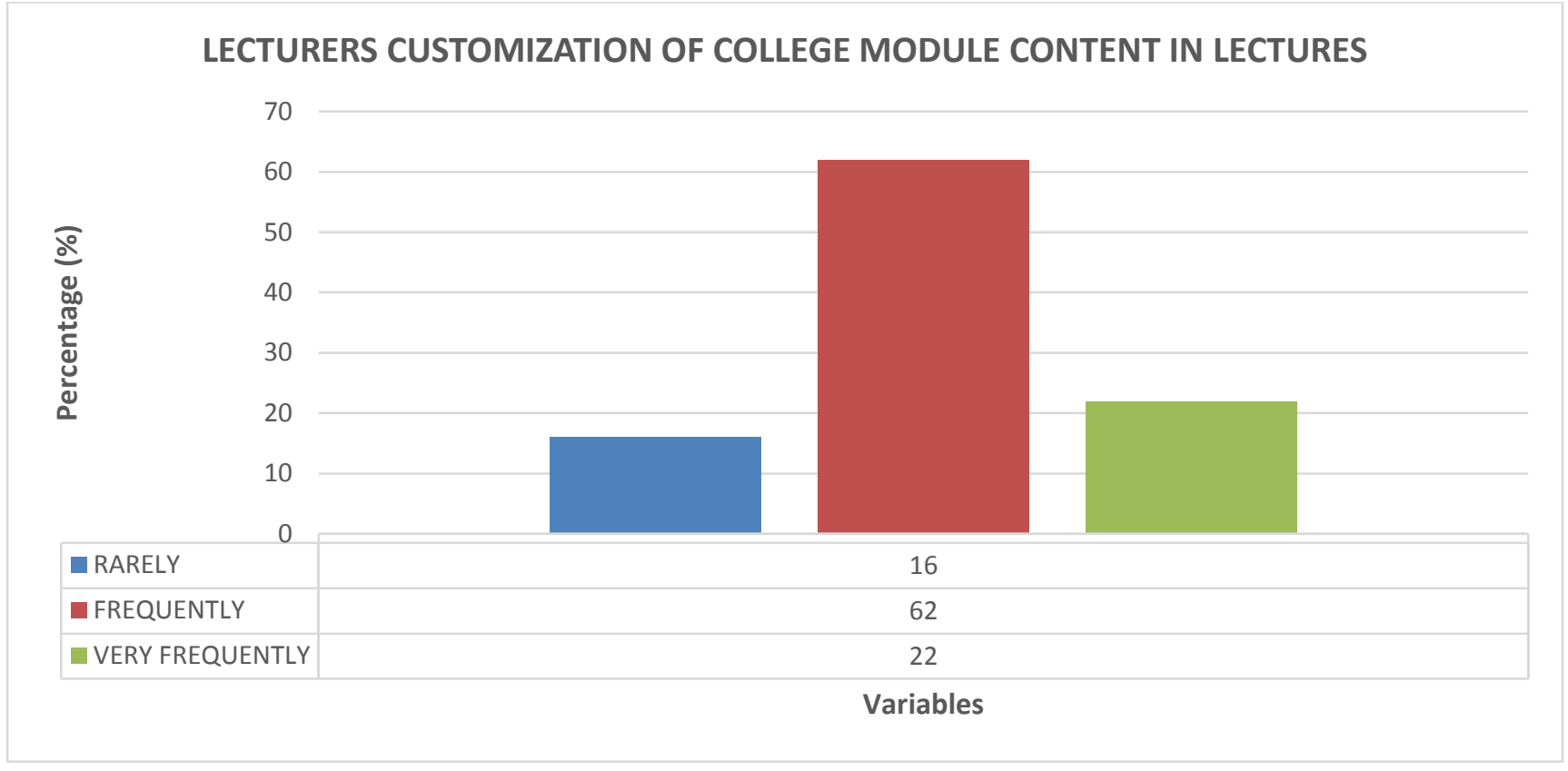

Key:

Percentage $=\mathrm{n} / 45^{*} 100$

\section{Figure 7: Lecturers customization of college module content in lectures}

$62 \%$ and $22 \%$ of the respondents do frequently and very frequently customize college modular content in lectures sessions, respectively. $16 \%$ of the respondents rarely customize college modular content in lectures.

\section{Lecturer's frequency in providing instructions that enhance SCL}

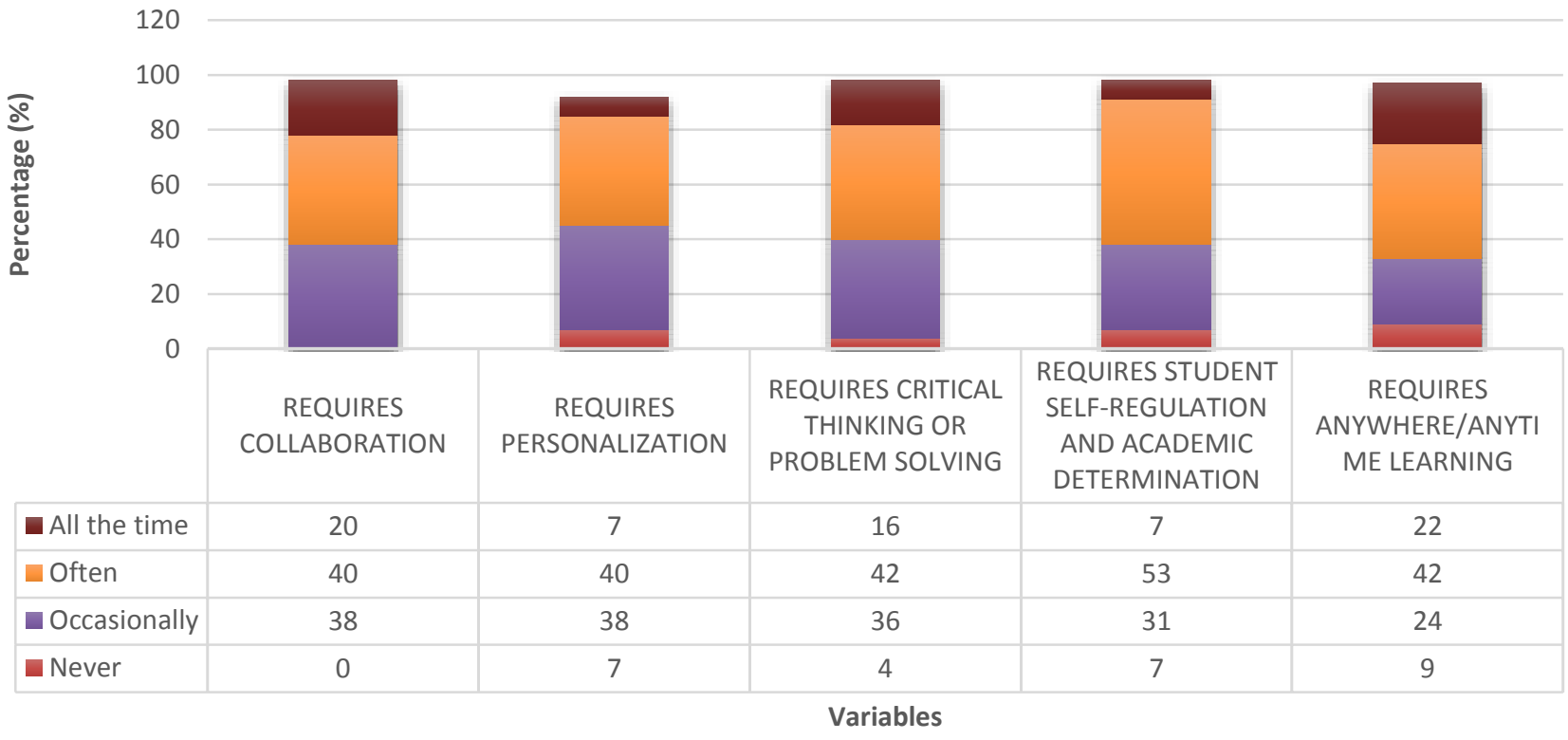

Key:

Percentage $=\mathrm{n} / 45^{*} 100$

Figure 8: Lecturer's frequency in providing instructions that enhance SCL 
$53 \%$ of the respondents indicated that they often require students' self-regulation and academic determination. $22 \%$ of the respondents stated that they all the time requires anywhere/anytime e-learning. Occasionally $38 \%$ of the respondents require collaboration and personalization in the provision of instruction that enhances SCL. 9\%, 7\% and 4\% of the respondents indicated that they never require anywhere/anytime e-learning, students' self-regulation and academic determination \& personalization, and critical thinking or problem-solving in the provision of instruction that enhances SCL, respectively.

\section{Lecturers' frequency in mentoring and monitoring SCL activities}

$71 \%$ and $9 \%$ of the respondents frequently and very frequently mentor and monitor SCL activities, respectively, while, $7 \%$ of the respondents rarely mentor and monitor SCL activities.

\section{EVALUATION PROCEDURE TO DETERMINE STUDENTS} SATISFACTION IN TEACHING AND LEARNING PROCESS

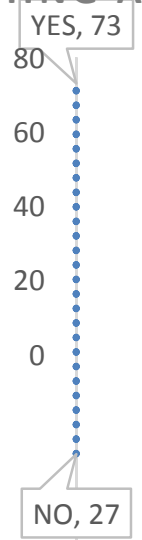

Key:

Percentage $=\mathrm{n} / 45^{*} 100$

Figure 9: Evaluation procedure to determine students' satisfaction in the teaching and learning process.

The majority of the respondents $73 \%$ have evaluation procedures to determine students' satisfaction in the teaching and learning process, while, $27 \%$ of the respondents do not have. 


\section{Most important evaluation methods used by lecturers to assess their students' learning}

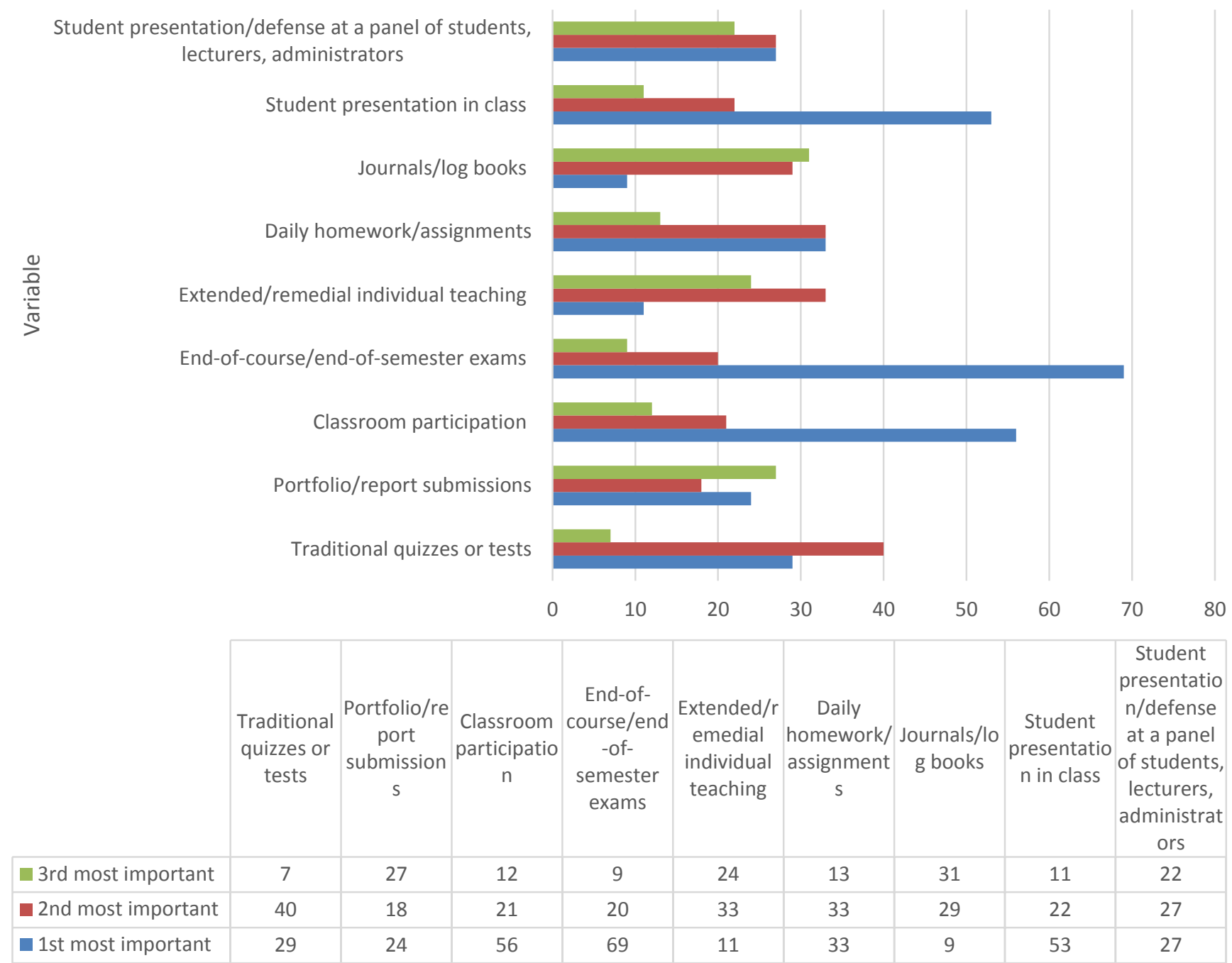

Percentage (\%)

Key:

Percentage $=\mathrm{n} / 45^{*} 100$

Figure 10: Most important evaluation methods used by lecturers to assess their students'

\section{learning}

End of course/end of semester exams, class participation and student presentation in the class was rated $69 \%, 56 \%$ and $53 \%$ as the $1^{\text {st }}$ most important evaluation methods used by lecturers to assess their students' learning, respectively. Traditional quizzes or tests $(40 \%)$, extended/remedial individual teaching (33\%) and daily homework assignment $(33 \%)$ as $2^{\text {nd }}$ most important evaluation methods used by lecturers to assess their students' learning. Journal/Logbooks (31\%), Portfolio/report submission (27\%) and extended/remedial individual teaching (24\%) as the $3^{\text {rd }}$ most important evaluation methods used by lecturers to assess their students' learning. 


\section{DISCUSSION}

\section{Demographic characteristic}

According to the data analysis, KMTC - Homa Bay Campus had the majority of the respondents at $56 \%$ followed by Kisii and Migori Campuses at $16 \%$ and lastly Nyamira Campus by $13 \%$. In all the four KMTC Campuses within the South Nyanza region, Nursing Department had the most respondents at $47 \%$ followed by Physiotherapy Department at $18 \%$ then Clinical Medicine and Nutrition departments both at $16 \%$ and lastly Medical Engineering and Orthopedic \& Trauma Departments at both $2 \%$. It is interesting to note that most of the respondents were external lecturers (51\%) while internal lecturers were $49 \%$. Most lecturers have taught in KMTC for $(2-5)$ years $(36 \%), 31 \%$ of participants have taught in KMTC for 1 year and below, while, $7 \%$ of the participants have taught in KMTC for 21 years and above.

Level of lecturers' education range from diploma to master degree. More than half of the respondents have a Bachelor of Science Degree (60\%). $20 \%$ of the respondents have a Higher National Diploma, while those who have a Master's Degree and Diploma were 13\% and 7\% respectively. In terms of gender; most respondents are male at $62 \%$, while, female respondents were $38 \%$. The majority of the lecturers are aged (30-39) years $(31 \%)$, followed by $(50-59)$ years $(27 \%)$, while the least lecturers age bracket were those of 60 years and above (4\%). It is important to mark that most of the participants were not trained in Medical Education at 58\%. Within the four KMTC - campuses of South Nyanza region, most of the respondents teach Human Anatomy and Physiology (29\%) followed by; Pathology \& communicable diseases (24\%), gynecology (24\%), sports medicine (9\%), therapeutic exercises (7\%) among other modules.

These demographic characteristics show that the majority of lecturers are part-time and have not been trained for medical education; hence, this can greatly interfere with lecturers' ability to enhance the implementation of students centered learning. Moreover, awareness of studentcentered learning was associated with the educational level of the lecturers. These findings thence highlight that lecturers within KMTC - Campuses of South Nyanza region need to be educated on student-centered learning plus its challenges for them to effectively implement it.

\section{Awareness Level}

The degree of awareness in student-centered learning among lecturers within the four KMTC - Campuses of South Nyanza region is low (49\%). It is disappointing to note that in terms of lecturer's preparedness to support students on SCL was $24 \%, 42 \%, 49 \%$ and $44 \%$ of lecturers are prepared to support students on learning anywhere/anytime, academic determination, students' self-regulation, critical thinking or problem solving and personalization, respectively. A similar study done in Oman concluded that for the effective realization of the practice of 
student-centered learning within a learning institution; lecturers must adequately prepare to support students in all the sphere of learning like collaboration, personalization, critical thinking or problem solving, students' self-regulation and academic determination and learning anywhere/anytime ${ }^{3}$.

The four KMTC - Campuses within South Nyanza Region, student population per class is highest at (40 - 49) students $(36 \%)$ while the least is 19 students and below at $2 \%$. These finding tallies with research done by Henshaw in 2016 which state that for effective student's centered learning, the ideal student - lecturer ratio per class is $42: 1^{6}$. Quality and efficiency of learning in SCL, students to lecturer ratio are supposed to be strictly adhered to develop critical thinkers who will challenge the status quo ${ }^{6}$.

Slightly more than half $(51 \%)$ of the lecturers within four KMTC-Campuses at the South Nyanza region stated that they are satisfied with time allocation per session which runs from mostly $(1.31-2)$ hour at $55 \%$ in fostering student-centered learning. The finding agrees with Danko and Duarte $(2009)^{7}$ who write that both teachers (lecture and practical) should be available weekly for 2 hours during predefined times for class attendance and additional support.

Over three-quarters of the lecturers (98\%) have the intention to advocate for SCL. This is in line with Scrivener $(2005)^{8}$ which elaborates that for quality and efficiency of learning, lecturers must be ready to advocate for SCL and maximize learning environment for a substantial impact on academic performance.

The finding indicates that $58 \%$ and $29 \%$ of the lecturers state that SCL has a moderate and substantial impact on student's academic performance, respectively. The finding is in line with Asoodeh and Zarepour, (2012) ${ }^{9}$ study which determined the effects of student-centered learning on academic achievement and social skills in $2^{\text {nd }}$ elementary that showed that SCL has an increase in student academic performance, increase in student social acceptance and selfconfidence.

The majority of the lecturers (78\%) views teaching student's skills and self-evaluation as very important in enhancing SCL. While $51 \%$ of the lecturers indicated that encouraging students to come up with learning contracts is very important in enhancing SCL. 56\% of lecturers' view giving students' autonomy to determine what they learn is very important in enhancing SCL. This is in line with Lea et al. $(2003)^{10}$ study that reviewed several works of literature touching on students' and lecturers' perceptions of student-centered learning and found out that over it is an effective approach used by lecturers to facilitate knowledge, skills, and attitude towards students. 
Exposing students to more information both in class and clinical setting experiences, encouraging wide reading, facilitating students on professional ethics regarding their roles and responsibilities within the community, providing students with more learning materials, mentoring students to positively change their attitude towards SCL, and, frequently examining them through various methods are thematic strategies lecturers' uses to encourage students become the good student-centered learner. This is also in line with Kember, (2009) ${ }^{11}$ study that looks at the system of promoting SCL that comprise of five-man components, namely: good practice with learning activities, teacher training courses, introducing new innovating learning experiences through projects, program evaluation by students and programs quality review.

\section{Resources for implementation of SCL}

$84 \%$ of the lecturers indicated that there are not enough resources available within the department to enhance SCL. Majority of respondents (64\%), state that the most commonly used resources within the department is the library, followed by Clinical Site/hospital (51\%), then Computers and internet (44\%). Lastly, they indicated that the Skills lab/Demonstration room and Community placement site are least used as resources for SCL within the department, $33 \%$, and $22 \%$ respectively. The findings indicate that the major resource available for use in the four KMTCs are the library and the clinical sites in the teaching and hospital used by the respective KMTCs as well as internet site connections within the four KMTCs. However, most of the books and journals in the library are not current. Barbara, (2014) ${ }^{12}$ acknowledges that the learning environment constitute resources available that will contribute to SCL. A study done in Oman further notes that students are actively involved in teaching and learning when local examples, books, illustrations, and analysis are used ${ }^{3}$.

$56 \%$ of respondents' show that their instructional design has a moderate impact (new approaches to tasks, activities, and classroom discourse), followed by substantial impact at $18 \%$ (that is, fundamentally reshaped how I teach and what I expect of students), then $16 \%$ at minimal impact (that is; minor changes in tasks, activities or classroom discourse), and, $9 \%$ of respondents indicated that their SCL instructional design has no impact on students' teaching and learning. The finding indicates that the majority of respondents acknowledge that SCL has a moderate impact on the learners. This implies that it inculcates some skills in learners to be independent to initiate and undertake practical based learning tasks among themselves. The findings are in line with Hsiung (2012) ${ }^{13}$ who confirms that SCL helps the learners to serve as facilitators in the process and the delivery of curriculum and instruction. SCL is key in guiding, preparing and equipping students with skills needed to face the real world.

The majority of lecturers ( $87 \%)$ suggest that it is their responsibility to make sure that resources for SCL are available for students. The rest $13 \%$ of the lecturers decline that it is not their 
responsibility to avail resources for SCL. The majority of lecturers indicate that it's the responsibility of the lecturers to avail resources for SCL because they are the facilitators. Maclellan (2008) ${ }^{14}$ disagrees with the findings by asserting that students share responsibility for their learning with their teachers, parents/guardians and other support persons. Maclellan (2008) ${ }^{14}$ further observes that SCL is not necessarily a linear process; the intrinsic power shift as students approach learning in a more pro-active manner.

$44 \%$ and $26 \%$ of the respondents asserted that frequently and very frequently acquire resources for SCL, respectively. 31\% of the respondents rarely acquire resources for SCL. Maclellan, (2008) ${ }^{14}$ studies differ with the findings by stating that student-centered learning models personalize learning with the use of competency-based approaches, supported by blended and online learning modalities and environments, as well as extended learning options and resources.

$91 \%$ of the respondents confirmed that they face challenges in the implementation of SCL within the four KMTC Campus in the South Nyanza Region compared to 9\% who reported that they do not face any challenges in the implementation of SCL. The findings agree with An and Reigeluth (2011) ${ }^{15}$ who observe that the majority of EFL university teachers were found to manifest the teacher-centered instruction where they talk most of the time before students who receive information without playing active roles in the classroom. Their roles were noted to lack learner-centeredness practices. An and Reigeluth $(2011)^{15}$ further note that the instructors may probably face certain barriers that hinder the implementation of learnercentered instruction.

The majority of the respondents $(73 \%)$ stated that inadequate stocked Library department imposes a major challenge in the implementation of SCL. It was followed by $63 \%$ of respondents who indicated that the lack of adequate computers and internet services contributes to challenges in the implementation of SCL. Limited access to instructional information, family and work pressure plus inadequate teaching material also impose challenges in the implementation of SCL at 44\%, 29\%, and 17\%, respectively. The findings are in line with An and Reigeluth (2011) ${ }^{15}$ who write there are several barriers in implementing learner-centered instruction. These include a) lack of time; b) assessment; c) institutional barriers; d) lack of knowledge about learner-centered instruction; d) subject culture; e) teacher's attitude toward learner-centered instruction. An and Reigeluth $(2011)^{15}$ further assert that the lack of funding, limited resources, student behavior, and class size can be seen as added barriers to implementing learner-centered instruction.

\section{Lecturers' contribution to SCL}


Moderate involvement (51\%) has been engaged by lecturers to enhance SCL activities, while, $40 \%$ of the lecturers have had minimal involvement in enhancing SCL activities in their respective KMTC Campuses within South Nyanza Region. 9\% of the respondents have had substantial involvement in enhancing SCL activities within their campuses. McCabea and O'Connorb, (2014) ${ }^{16}$ agree with the finding by stating that for lecturers to encourage an independent learning culture which is considered a key priority to redress the goal-oriented mindset amongst students rather than being conditioned to succeed through mimicking and regurgitating.

93\% of the lecturers notice inactive students during their lecture sessions. This is contrary to An and Reigeluth (2011) ${ }^{15}$ who states that if student-centered learning effectively practices there will be no inactiveness of students since they are engaged in the active learning process to build on their educational needs, experiences, backgrounds, talents, and capacity; nevertheless, inactiveness of students experiences when teaching staff practice teachercentered learning approach which passively engage students and foster inactiveness towards their participation during the learning process in which they receive content that is not meaningful to their lives and experience.

The finding indicates the following as measures lecturers use to engage inactive students; first, directly engage student through class participatory interactive learning sessions, second, have an interactive counseling session with the student to establish etiology of their inactiveness in class and let them come up with appropriate solutions to make them active in class, third, have them take micro-break sessions in between lectures, and lastly, encourage adequate preparation for the lecture session by giving the topic of the next lecture. This is in line with Macmillian $(2003)^{17}$ who argued that teachers should nurture and mentor students to have them participate effectively in lectures and practical sessions so that they can practice SCL.

$62 \%$ and $22 \%$ of the lecturers frequently and very frequently customize college modular content in lectures sessions, respectively. This is in line with Galkute et al., (2015) ${ }^{18}$ who note that teachers are required to construct a study process that is oriented towards development as established within the teaching guide.

Slightly more than half (53\%) of the lecturers indicated that they often require students' selfregulation and academic determination. This finding agrees with Macmillian (2003) ${ }^{17}$ who says that lecturers should help students evaluate their progress by encouraging them to critique their work, analyze their strengths and weakness. Macmillian $(2003)^{17}$ also further notes that teachers should encourage students also to focus on their continued improvement, not just on their grades but also on any one test or assignment given. 
$71 \%$ and $9 \%$ of the respondents frequently and very frequently mentor and monitor SCL activities, respectively, while, $7 \%$ of the respondents rarely mentor and monitor SCL activities. These findings tally with Weimer (2002) ${ }^{19}$ who asserts that the SCL learning process should be frequently monitored using classroom routines, frequent questioning and use of discussions to monitor progress. Weimer (2002) ${ }^{19}$ further observes that this paradigm shift will encourage moving power from the instructor to the learner, treating the learner as a co-creator in the teaching and learning process.

The majority of the lecturers (73\%) have evaluation procedures to determine students' satisfaction in the teaching and learning process, while, $27 \%$ of the lecturers do not have. Finding agrees with Bennett (1989) ${ }^{20}$ who asserts that assessment instruments are a very important component of SCL because its enable assessor to gauge the competencies of a candidate via using the correct instrument of assessment, hence, safeguard the public through ensuring that, only those who have attained a minimal level of competence services them.

End of course/end of semester exams, class participation and student presentation in the class was rated $69 \%, 56 \%$ and $53 \%$ as the $1^{\text {st }}$ most important evaluation methods used by lecturers to assess their students' learning, respectively. This finding is in line with Creswell (2007) ${ }^{21}$ who says that assessment of student learning at its best enables students to identify their strengths and weaknesses and to determine the kinds of information they need to correct their learning deficiencies and misconceptions.

\section{CONCLUSION}

The findings indicate that the degree of awareness and practice of SCL by the lecturers was low within the four KMTC - Campuses. Students to the lecturer ratio were within the internationally recommended standard of 42:1. The study shows that lecture sessions duration within the four KMTC - Campuses was between $1 \frac{1 / 2}{2}$ hour to 2 hours. The majority of the lecturers were willing to advocate for SCL. Lecturers acknowledged that SCL had an impact on the student's academic performance. The lecturers concluded that the following were strategies they use to encourage students to become good student-centered learners; exposing students to more information both in class and in clinical settings, encouraging wide reading, facilitating students on professional ethics regarding their roles and responsibilities within the community, providing students with more learning materials, mentoring students to positively change their attitude towards SCL, and frequently examining them through various methods. The study indicated that lecturers' instructional design had impacted SCL particularly on new approaches to tasks, activities and classroom discourse. However, the study further noted that there were inadequate resources for the implementation of SCL within the four KMTCCampuses. The findings add that this exposed lecturers to challenges during implementation 
of SCL, although it was part of their responsibility to acquire resources for SCL. The challenges identified include; inadequate stocked library, inadequate computers and internet services, limited access to instructional information, family, the pressure of work and inadequate teaching material.

The study indicated that lecturers had little involvement to enhance SCL activities within their various campuses. Most of the lecturers customized college modular content in lectures sessions. The finding further indicates that the majority of the lecturers had evaluation procedures to determine students' satisfaction in teaching and learning processes such as the use of end of the course/semester exams, class participation and student presentation in class as their most important evaluation methods to assess their students' learning process. The study further found out that lecturers notice inactive students during their lecture sessions and the study indicated that they use the following measures to engage them; first, directly engage student through class participatory interactive learning sessions, have interactive counseling sessions with the students to establish etiology of their inactiveness in class, allowing them to come up with appropriate solutions to make them active in class, allow them to take microbreak sessions in between lectures and finally encourage adequate preparation for the lecture session by giving the topic of the next lecture.

\section{RECOMMENDATION}

To minimize the challenge faced by lecturers in implementation of students' centered learning within four KMTC-Campuses of South Nyanza Region, the research recommends the following as areas for further researches for enhancement of SCL:

- Exposure of students to various participatory learning methodologies,

- Continuous medical education for lecturers on SCL, and,

- Provision of SCL resources.

\section{ACKNOWLEDGMENT}

This research work is a product of a lengthy participatory process that involved many people. The researchers want to thank the Director of Kenya Medical Training College for financially supporting this study. Special sincere gratitude goes to the staff and management of the four KMTC-Campuses within South Nyanza Region, which is: Homa Bay Campus, Kisii Campus, Nyamira Campus and Migori Campus for providing conducive environment for this study to be undertaken. Sincere appreciation goes to the lecturers who agreed to take part in this study as respondents without whom this research work could not have materialized.

\section{REFERENCES}

1. Taylor, P. G., (2000). Changing Expectations: Preparing students for flexible learning. The International Journal of Academic Development 5(2), 107 - 115. 
2. Kember, D. (1997). Learning and Instruction. A reconceptualization of the research into University Academics' Conceptions of teaching. Elsevier science ltd. Britain. Vol.7, NO.3, Pg 255 - 275.

3. Ogadimma C. E., (2012). Student-centered learning in Oman: Challenges and pitfalls. Macrothink institute. International Journal of Learning \& Development.

4. Sioux M., (2013). The dangers of student-centered learning - a caution about blind spots in the scholarship of teaching and learning. Internal journal for the scholarship of teaching and learning Vol 7. No: 2. Article 6.

5. Mugenda, A. (2008). Social Science Research: Theory and Principles. Nairobi: Applied Research \& Training Services.

6. Henshaw, John M. (2006). Does Measurement Measure Up?: How Numbers Reveal and Conceal the Truth. pp. 45-46. ISBN 9780801883750.

7. Danko C And Duarte A. A. (2009) The Challenge of Implementing a Student-Centred Learning Approach in Large Engineering Classes. Journal of WSEAS transactions on advances in engineering education. Issued $8, \mathrm{Vol}$ :

8. Scrivener Jim (2005). Learning Teaching. United Kingdom, Macmillan Publishers Limited.

9. Asoodeh H. M, Zarepour M., (2012). The impact of student-centered learning on academic achievement and social skills. Procedia - social and behavioral sciences. Published by Elsevier Ltd. Volume 46, 2012, Pages 560-564.

10. Susan J. Lea, David Stephenson \& Juliette Troy (2003) Higher Education Students' Attitudes to Student-centred Learning: Beyond 'educational bulimia'?, Studies in Higher Education, 28:3, 321-334, DOI: 10.1080/03075070309293

11. Kember, D (2009) 'Promoting student-centered Forms of Learning Across an Entire University'. In: Higher Education, 58, pp.1-13.

12. Barbara, M., (2014). Researchers find student-centered learning approaches help underserved kids achieve. https://ed.stanford.edu/news/researchers-find-studentcentered-learning-approaches-help-underserved-kids-achieve. Viewed on 14/10/2016, at14.55.

13. Hsiung, C. (2012) The Effectiveness of Cooperative Learning. Journal of Engineering Education 101(1). American Society for Engineering Education.

14. Maclellan, E. 2008. The significance of motivation in student-centered learning: a reflective case study. Teaching in Higher Education 13, no. 4: 411-21. 
15. An, Y. J., \& Reigeluth, C. (2011). Creating Technology-Enhanced, Learner-Centered Classrooms: K-12 Teachers' Beliefs, Barriers, and Support Needs. Journal of Digital Learning in Technology Education, 28(2), 54-62.

16. McCabea A and O'Connorb U., (2014). Student-centered learning: 'Letting Go', the role and responsibility of the lecturer. Dundalk Institute of Technology. University of Ulster, Northern Ireland.

17. Macmillian, J.R. (2003). Best management practice development of documentation. McGraw - Hill. New York.

18. Galkute et al., (2015). Online: http://www.smm.it/upload/documents/kiti(SPA(8)kas\%20lemia\%20studiju\%20kokyb e.pdf. Visited 22/10/2017.

19. Weimer, M. (2002). Learner-centered teaching: Five key changes to practice. San Francisco: Jossey-Bass. Student-Centered Learning.

20. Bennett, Y. (1989). The Assessment of supervised work experience (SWE). A Theoretical Perspective. The Vocational Aspect of Education; XII, 109, 5 - 64.

21. Creswell JW. Qualitative inquiry and research design. $2^{\text {nd }}$ ed. California: Sage Publications, Inc.; 2007.

\section{BJMHR is \\ - Peer reviewed \\ - Monthly \\ - Rapid publication \\ - Submit your next manuscript at editor@bjmhr.com

